\title{
Evaluation of carotid intima-media thickness and flow-mediated dilatation in middle-aged patients with nonalcoholic fatty liver disease
}

This article was published in the following Dove Press journal:

Vascular Health and Risk Management

4 November 2011

Number of times this article has been viewed

\author{
Afshin Mohammadi' \\ Homayoon Habibpour \\ Sedani ${ }^{2}$ \\ Mohammad Ghasemi-Rad ${ }^{3}$ \\ 'Department of Radiology, ${ }^{2}$ Student \\ Research Committee, ${ }^{3}$ Genius and \\ Talented Student Organization, \\ Student Research Committee, \\ Urmia University of Medical Sciences, \\ Urmia, West-Azerbaijan, Iran
}

Background: Nonalcoholic fatty liver disease (NAFLD) has a high prevalence in the general population and is the most common liver disease in Western countries. It is a feature of metabolic syndrome and is characterized by excessive accumulation of fat in the liver cells.

Methods: We examined 84 consecutive middle-aged (under 45 years) patients with NAFLD and 65 control subjects matched for age, gender, and body mass index to determine carotid intima-media thickness (CIMT) and flow-mediated dilatation (FMD) in the brachial artery.

Results: There was a statistically significant difference between CIMT and percentage increase in FMD in the patient group $(P=0.002 ; \mathrm{r}=0.33)$ when compared with the control group $(P=0.97 ; \mathrm{r}=0.005)$. The mean \pm standard deviation CMIT was $0.65 \pm 0.09 \mathrm{~mm}$ in patients and $0.55 \pm 0.07 \mathrm{~mm}$ in controls. This difference was statistically significant $(P=0.001)$. Mean FMD in patients was $6.4 \%$ and $15.7 \%$ in controls. This difference was statistically significant $(P=0.001)$.

Conclusion: This study shows that pure NAFLD without metabolic syndrome in middle-aged subjects is strongly associated with morphological (CIMT) and physiological (FMD) changes. These findings may have an important role in increasing cardiovascular risk in these patients.

Keywords: nonalcoholic fatty liver disease, carotid intima-media thickness, flow-mediated dilatation

\section{Introduction}

Nonalcoholic fatty liver disease (NAFLD) has a high prevalence in the general population and is the most common liver disease in Western countries. ${ }^{1}$ It is one of the features of metabolic syndrome and is characterized by excessive accumulation of fat in the liver cells. ${ }^{2,3}$ Patients with NAFLD have a higher mortality rate compared with the general population. ${ }^{4}$

NAFLD is also strongly associated with risk factors for atherosclerosis, such as obesity, dyslipidemia, hypertension, type 2 diabetes mellitus, and insulin resistance. ${ }^{5}$ NAFLD has been recently accepted as a hepatic component of metabolic syndrome. ${ }^{6}$ In published data, the mortality rate for coronary heart disease in patients with NAFLD is equal to the mortality related to cirrhosis. ${ }^{7}$ Theoretically, the increased risk of cardiovascular events in patients with NAFLD is due to coexistence of this entity with metabolic syndrome. Ultrasonographic measurement of flow-mediated dilatation (FMD) is a noninvasive method to demonstrate subclinical atherosclerosis, ${ }^{8}$ with recent data showing it to be a predictor of cardiovascular events. ${ }^{9,10}$ There are no published data regarding the association between NAFLD and subclinical atherosclerosis in middleaged patients with low cardiovascular risk. In the present study, we evaluated a group
Correspondence: Mohammad Ghasemi-Rad Genius and Talented Student Organization, Student Research Center, Urmia University of Medical Sciences, Urmia, Iran Tel +9844 I235356। Fax +9844 I235356I Email medmanII@gmail.com 
of middle-aged patients with ultrasonographically confirmed NAFLD. The novelty of our research is that it evaluated atherosclerotic findings in middle-aged patients with NAFLD and without metabolic syndrome. We wanted to demonstrate that atherosclerosis can affect vascular anatomy and physiology in NAFD patients, independent of other risk factors. FMD could serve as an important marker for early introduction of a cardioprotective protocol in NAFLD patients.

\section{Materials and methods}

We enrolled 84 consecutive middle-aged (30-45 years) patients with NAFLD and 65 controls matched for age, gender, and body mass index to determine carotid intimamedia thickness (CIMT) and FMD of the brachial artery. The study protocol was approved by the University Ethics Committee and the Faculty of Medicine. Written informed consent was obtained from all participants.

Diagnosis of NAFLD was made on the basis of ultrasonographic criteria. Abdominal ultrasound scanning was performed in all participants by one trained radiologist who was blinded to all clinical and laboratory data, using a Toshiba Nemio 30 scanner (Toshiba Co Ltd, Tokyo, Japan) with a $3.5 \mathrm{mHz}$ linear transducer. Hepatic steatosis was diagnosed by a characteristic liver echo pattern (diffuse hyperechogenicity of liver compared with right kidney).

Subjects with heart disease, diabetes mellitus, hypertension (blood pressure $>130 / 85 \mathrm{mmHg}$ ), hyperlipidemia, acute or chronic liver disease, acute or chronic kidney disease, any malignancy, alcohol consumption, pregnancy, liver masses, abnormal copper metabolism or thyroid function test, taking any medication with adverse effects on liver or cardiovascular system, history of cigarette smoking, or criteria of metabolic syndrome were excluded. Only patients negative for hepatitis B surface antigen and hepatitis $\mathrm{C}$ antibody were enrolled. Subjects with a body mass index above $30 \mathrm{~kg} / \mathrm{m}^{2}$ were also excluded. At the time of the study, the NAFLD patients had no clinical or biochemical evidence of liver cirrhosis.

Blood samples were collected in the morning after overnight fasting for biochemical measurements. Biochemical inclusion criteria were fasting blood glucose $<110 \mathrm{mg} / \mathrm{dL}$, triglycerides $<150 \mathrm{mg} / \mathrm{dL}$, total cholesterol $<240 \mathrm{mg} / \mathrm{dL}$, high-density lipoprotein $>40 \mathrm{mg} / \mathrm{dL}$ for men and $>50 \mathrm{mg} / \mathrm{dL}$ for women, and serum transaminases (alanine aminotransferase, normal adult range 8-20 U/L, aspartate aminotransferase, normal adult range 8-20 U/L). All biochemical investigations were performed in the same laboratory.
Ultrasonographic examination of FMD was performed in the morning after an overnight fast and 15 minutes of rest in the horizontal position, using a Sonoline G40 ultrasound scanner (Siemens, Germany) with a $10 \mathrm{mHz}$ linear transducer. The diameter of the right brachial artery was measured $3-5 \mathrm{~cm}$ above the antecubital space at baseline. The measurements were performed in the end-diastolic phase, marking the diameter between the anterior and posterior artery wall in the zone between the media and adventitia ( $M$ line, Figure 1). An average of three measurements was used to calculate FMD. A pneumatic tourniquet was subsequently placed on the upper part of the right forearm and inflated for four minutes to a pressure of $200 \mathrm{mmHg}$ or $50 \mathrm{mmHg}$ above systemic arterial blood pressure. Sixty seconds after the cuff was released, the diameter of the right brachial artery was measured three times. FMD was calculated as the percent increase in vascular diameter from the difference between the maximum and baseline brachial artery diameter.

The maximum CIMT was measured at the posterior wall of the common carotid artery, $2 \mathrm{~cm}$ before the bifurcation, as the distance between the first and second echogenic lines of the anterior and posterior arterial walls. The image was focused on the posterior wall of the common carotid artery, and gain settings were used to optimize image quality. Measurement was performed vertical to the arterial wall for accurate recording of CIMT. Three CIMT measurements were taken at each site and the average measurement was used (Figure 2).

Data were calculated as the absolute diameter of the brachial artery (in $\mathrm{mm}$ ) and the percent increase from baseline after cuff release and in response to ischemia.

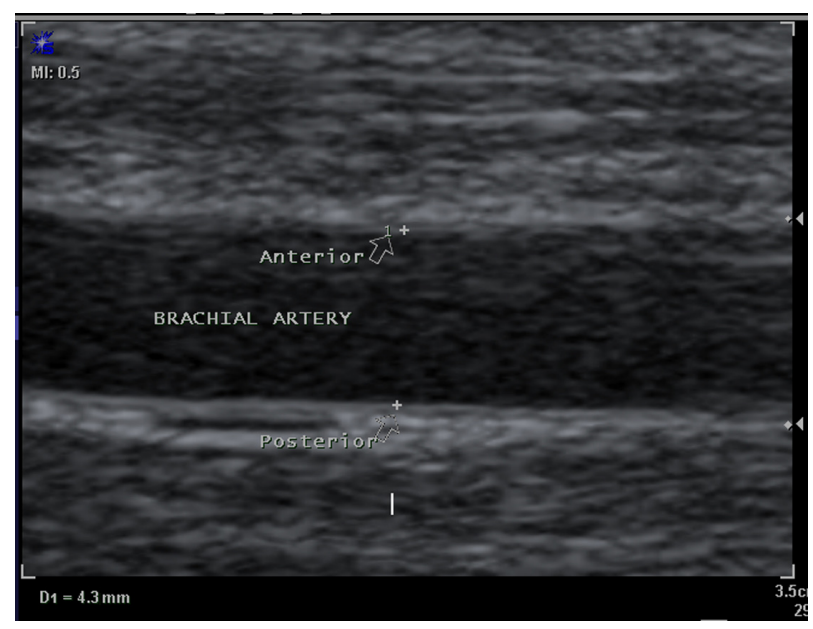

Figure I Longitudinal ultrasonogram of the brachial artery diameter from anterior to posterior wall. 


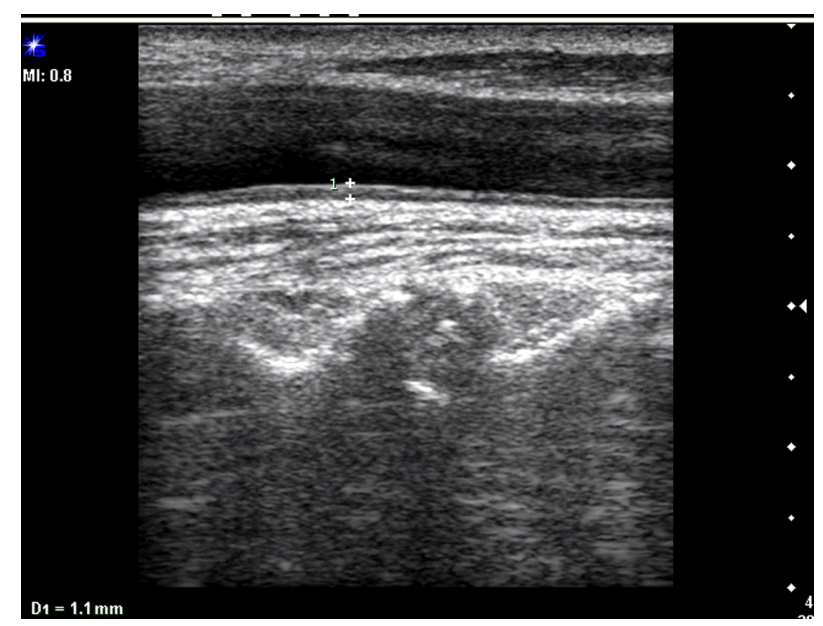

Figure $\mathbf{2}$ Longitudinal ultrasonogram of common carotid artery shows the carotid intima-media thickness in the posterior wall.

\section{Statistical analysis}

Statistical analysis was performed using SPSS version 16 (SPSS Inc, Chicago, IL). Data were expressed as the mean \pm standard deviation (SD) for numerical variables. We also used the independent Chi-square test and $t$-test to analyze the data. $P \leq 0.05$ was considered to be statistically significant.

\section{Results}

Eighty-four patients with fatty liver disease and 65 agematched controls were enrolled in the study. Forty-four patients were male and 40 were female, and 35 of the controls were male and 30 were female. Mean age was $37.71 \pm 4.95$ years in the patient group and $38.38 \pm 4$ years in the control group. There was no statistically significant difference between two groups with regard to age $(P=0.39)$. Forty-two patients had grade $1(50 \%), 29$ patients had grade $2(34.5 \%)$, and 13 patients (15.5\%) had grade 3 fatty liver disease. There was a significant difference between CIMT and percent increase in FMD in patients $(P=0.002 ; \mathrm{r}=0.33)$ when compared with controls $(P=0.97 ; \mathrm{r}=0.005)$. The data for laboratory parameters, body mass index, age, and gender are presented in Table 1.

Mean CMIT was $0.65 \pm 0.09 \mathrm{~mm}$ in patients and $0.55 \pm 0.07 \mathrm{~mm}$ in controls. This difference was statistically significant $(P=0.001)$. The mean increase in brachial artery diameter was $0.22 \pm 0.11 \mathrm{~mm}$ in patients and $0.57 \pm 0.13 \mathrm{~mm}$ in controls. This difference was statistically significant $(P=0.001)$, indicating an increase in diameter with ischemia. Mean brachial artery diameter at baseline was $3.9 \pm 1.9 \mathrm{~mm}$ in patients and $3.8 \pm 2.2 \mathrm{~mm}$ in controls. The difference was not statistically significant $(P=0.058)$. Mean brachial artery diameter in response to ischemia was $4.15 \pm 1.9 \mathrm{~mm}$ in patients and $4.4 \pm 2.2 \mathrm{~mm}$ in the controls. This difference was statistically significant $(P=0.001)$. Mean FMD in patients was $6.4 \%$ and $15.7 \%$ in controls. The difference was statistically significant $(P=0.001)$.

\section{Discussion}

Nonalcoholic fatty liver disease is defined as excessive accumulation of fat in hepatocytes. NAFLD was previously considered to be a benign disease without clinical consequences. Nowadays, it is known that NAFLD is associated with a range of pathologic lesions, ranging from simple steatosis to nonalcoholic steatohepatitis and cirrhosis. The prevalence of NAFLD in adults is estimated to be $20 \%-30 \%$ of the general population in Western countries $^{11}$ and $12 \%-24 \%$ in Asian-Pacific countries. ${ }^{12}$ The prevalence in obese and diabetic patients increases up to $70 \%-90 \% .^{11}$

NAFLD is strongly associated with cardiovascular risk factors, such as obesity, dyslipidemia, type 2 diabetes mellitus, and insulin resistance. ${ }^{13}$ In the published data, mortality rates from coronary heart disease in patients with NAFLD were equal to those related to cirrhosis. NAFLD is now considered to be a hepatic manifestation of the metabolic syndrome. ${ }^{5}$ It is well known that the metabolic syndrome represents a "tsunami" of cardiovascular risk factors. Our study shows that NAFLD, even in the absence of the metabolic syndrome, is associated with increased CIMT and endothelial dysfunction, which are the major determinants of cardiovascular events.

In understanding the true pathophysiologic basis of NAFLD, the chicken and egg phenomenon persists, in that some authors believe that NAFLD can produce insulin resistance ${ }^{14}$ while others claim that insulin resistance is the major determinant of development and progression of fatty liver to nonalcoholic steatohepatitis.

The endothelium is considered to be the largest endocrine gland in the body, and secretes many transmitters to maintain homeostasis in the circulatory system. ${ }^{8} \mathrm{FMD}$ is a noninvasive ultrasonographic method which is currently recognized as a useful technique for evaluating endothelial function. ${ }^{8}$ The basic mechanism for FMD is to observe vasodilation by sonography after provoking ischemia by inflating blood pressure cuff. After brachial artery occlusion, endothelial nitric oxide is released and vascular smooth muscle relaxation occurs. ${ }^{15}$ 
Table I Main clinical, ultrasonographic, and laboratory data for patients with NAFLD and control subjects

\begin{tabular}{|c|c|c|c|c|c|}
\hline & Group & Mean & SD & $95 \% \mathrm{Cl}$ & $\begin{array}{l}\text { Significance } \\
\text { (two-tailed) }\end{array}$ \\
\hline \multirow[t]{2}{*}{ Age } & Case & 38.71 & 4.952 & -1.170 & 0.665 \\
\hline & Control & 38.38 & 4.084 & -1.134 & 0.657 \\
\hline \multirow[t]{2}{*}{ ALT } & Case & 32.43 & 16.914 & 1.445 & 0.010 \\
\hline & Control & 26.37 & 9.375 & 1.745 & 0.006 \\
\hline \multirow[t]{2}{*}{ AST } & Case & 20.50 & 8.076 & -0.877 & 0.222 \\
\hline & Control & 19.06 & 5.567 & -0.774 & 0.201 \\
\hline \multirow[t]{2}{*}{ FBS } & Case & 91.81 & 8.602 & -1.277 & 0.297 \\
\hline & Control & 90.37 & 7.948 & -1.250 & 0.292 \\
\hline \multirow[t]{2}{*}{ TG } & Case & 104.67 & 20.884 & -5.960 & 0.735 \\
\hline & Control & 103.43 & 23.457 & -6.076 & 0.739 \\
\hline \multirow[t]{2}{*}{ Cholesterol } & Case & 137.93 & 34.811 & -18.723 & 0.114 \\
\hline & Control & 146.28 & 27.348 & -18.412 & 0.103 \\
\hline \multirow[t]{2}{*}{$\mathrm{HDL}$} & Case & 49.06 & 6.337 & -5.428 & 0.002 \\
\hline & Control & 52.40 & 6.466 & -5.434 & 0.002 \\
\hline \multirow[t]{2}{*}{ CIMT } & Case & 0.640 & 0.0958 & 0.0581 & 0.000 \\
\hline & Control & 0.554 & 0.0752 & 0.0589 & 0.000 \\
\hline \multirow[t]{2}{*}{ Increased in diameter } & Case & 0.2298 & 0.11384 & -0.38290 & 0.000 \\
\hline & Control & 0.5723 & 0.13522 & -0.38385 & 0.000 \\
\hline \multirow[t]{2}{*}{ BMI } & Case & 24.4545 & 1.27104 & -0.12928 & 0.172 \\
\hline & Control & 24.1614 & 1.32235 & -0.13174 & 0.175 \\
\hline \multirow[t]{2}{*}{ Brachial artery diameter prior to ischemia } & Case & 3.924 & 0.1911 & -0.0023 & 0.058 \\
\hline & Control & 3.858 & 0.2263 & -0.0039 & 0.064 \\
\hline \multirow[t]{2}{*}{ Brachial artery diameter after ischemia } & Case & 4.154 & 0.1997 & -0.3464 & 0.000 \\
\hline & Control & 4.431 & 0.2270 & -0.3476 & 0.000 \\
\hline
\end{tabular}

Abbreviations: $\mathrm{Cl}$, confidence interval; FBS, fasting blood glucose; TG, triglycerides; HDL, high-density lipoproteins; ALT, alanine aminotransferase; AST, aspartate aminotransferase; CIMT, carotid intima media thickness; BMI, body mass index; SD, standard deviation.

One of the early processes in the pathophysiology of atherosclerosis is impaired endothelial function. ${ }^{16}$ Impaired endothelial function quantified by FMD is a marker of increased cardiovascular risk, due to its correlation with impaired endothelial function in the coronary arteries. ${ }^{17}$

Given that age, gender, and body mass index, as well as other cardiovascular risk factors, can influence the pathogenesis of atherosclerosis and its major determinants, ie, FMD and CIMT, ${ }^{18}$ we matched cases and controls to eliminate as far as possible the effect of old age on FMD and CIMT.

Our results are similar to those of Vlachopoulos et al ${ }^{18}$ who showed that NAFLD is associated with arterial stiffness and impaired endothelial function. We showed that there is a strong association between CIMT which is a morphological change and FMD which is a physiological change. Our study is similar to one reported by Glovinska-Olszewska et al, ${ }^{19,20}$ except that they showed the association in obese children and we demonstrated it in normotensive middleaged patients. The percentage FMD increase in our study is similar to that of Villanova et $\mathrm{al},{ }^{21}$ who reported that mean FMD in their patients with NAFLD was $6.33 \%$ and was $12.22 \%$ in controls. However, our measurements are greater than those of Vlachopoulos et al, ${ }^{18}$ who reported a mean FMD of $1.92 \%$ in patients with NAFLD and $4.8 \%$ in controls. This difference may be due to the age difference between patients in our study and those in their study, given that it is known that age is an important factor in CIMT and FMD ${ }^{21}$ In conclusion, our study demonstrates that NAFLD without metabolic syndrome in middle-aged subjects is strongly associated with morphological (CIMT) and physiological (FMD) changes, and these findings may have a substantial role in increasing cardiovascular risk in patients with NAFLD.

\section{Acknowlegment}

We would like to thank Dr Zahra Yekta, Department of Community Medicine, Urmia University of Medical Sciences for her help in analyzing the data.

\section{Disclosure}

The authors report no conflicts of interest in this work. 


\section{References}

1. Bellentani S, Scaglioni F, Marino M, Bedogni G. Epidemiology of non-alcoholic fatty liver disease. Dig Dis. 2010;28(1):155-161.

2. Balmer ML, Dufour JF. Non-alcoholic steatohepatitis - from NAFLD to MAFLD. Ther Umsch. 2011;68(4):183-188. German.

3. Wong VW, Wong GL, Yip GW, et al. Coronary artery disease and cardiovascular outcomes in patients with non-alcoholic fatty liver disease. Gut. May 20, 2011. [Epub ahead of print.]

4. Tarquini R, Lazzeri C, Boddi M, Marra F, Abbate R, Gensini GF. Non-alcoholic fatty liver disease: a new challenge for cardiologists. G Ital Cardiol (Rome). 2010;11(9):660-669.

5. Szollar L. Fatty liver and global cardiometabolic risk. Orv Hetil. 2010; 15(47):1946-1950. Hungarian.

6. Assy N, Djibre A, Farah R, Grosovski M, Marmor A. Presence of coronary plaques in patients with nonalcoholic fatty liver disease. Radiology. 2010;25(2):393-400.

7. Targher G, Marra F, Marchesini G. Increased risk of cardiovascular disease in nonalcoholic fatty liver disease: causal effect or epiphenomenon? Diabetologia. 2008;51(11):1947-1953.

8. Kaźmierski M, Michalewska-Włudarczyk A, Krzych LJ, Tendera M. Diagnostic value of flow mediated dilatation measurement for coronary artery lesions in men under 45 years of age. Cardiol J. 2010; 17(3):288-292.

9. Shimbo D, Grahame-Clarke C, Miyake Y, et al. The association between endothelial dysfunction and cardiovascular outcomes in a populationbased multi-ethnic cohort. Atherosclerosis. 2007;192(1):197-203.

10. Akamatsu D, Sato A, Goto H, et al. Nitroglycerin-mediated vasodilatation of the brachial artery may predict long-term cardiovascular events irrespective of the presence of atherosclerotic disease. JAtheroscler Thromb. 2010;17(12):1266-1274.

11. Targher G, Day CP, Bonora E. Risk of cardiovascular disease in patients with nonalcoholic fatty liver disease. $N$ Engl J Med. 2010;363(14): 1341-1350.
12. Chitturi S, Farrell GC, Hashimoto E, Saibara T, Lau GK, Sollano JD. Non-alcoholic fatty liver disease in the Asia-Pacific region: definitions and overview of proposed guidelines. J Gastroenterol Hepatol. 2007; 22(6):778-787.

13. Mohammadi A, Ghasemi-Rad M, Zahedi H, Toldi G, Alinia T. Effect of severity of steatosis as assessed ultrasonographically on hepatic vascular indices in non-alcoholic fatty liver disease. Med Ultrason. 2011;13(3):200-206.

14. Pascale A, Pais R, Ratziu V. An overview of nonalcoholic steatohepatitis: past, present and future direction. J Gastrointestin Liver Dis. 2010; 19(4):415-423.

15. Tschakovsky ME, Pyke KE. Counterpoint: Flow-mediated dilation does not reflect nitric oxide-mediated endothelial function. J Appl Physiol. 2005;99(3):1235-1238.

16. Asselbergs FW, Van der Harst P, Jessurum GA, Tio RA, Van Glist WH. Clinical impact of vasomotor function assessment and the role of ACEinhibitors and statins. Vascul Pharmacol. 2005;42(3):125-140.

17. Peretz A, Leota DF, Sullivan JH, et al. Flow mediated dilation of the brachial artery: an investigation of methods requiring further standardization. BMC Cardiovasc Disord. 2007;7:11.

18. Vlachopoulos C, Manesis E, Baou K, et al. Increased arterial stiffness and impaired endothelial function in nonalcoholic fatty liver disease: a pilot study. Am J Hypertens. 2010;23(11):1183-1189.

19. Głowińska-Olszewska B, Tołwińska J, Urban M. Interrelationship between endothelial dysfunction, IMT of the carotid arteries and adhesion molecules in obese hypertensive children and adolescents. Pediatr Endocrinol Diabetes Metab. 2007;13(1):7-14.

20. Pacifilo L, Anania C, Martino F, Cantisani V, Marcantonio A, Chiesa C. Functional and mrrphological vascular changes in pediatric nonalcoholic fatty liver disease. Hepatology. 2010;52(5):1643-1651.

21. Villanova N, Moscatiello S, Ramili S, et al. Endothelial dysfunction and cardiovascular risk profile in nonalcoholic fatty liver disease. Hepatology. 2005;42(2):473-480.
Vascular Health and Risk Management

\section{Publish your work in this journal}

Vascular Health and Risk Management is an international, peerreviewed journal of therapeutics and risk management, focusing on concise rapid reporting of clinical studies on the processes involved in the maintenance of vascular health; the monitoring, prevention and treatment of vascular disease and its sequelae; and the involvement of

\section{Dovepress}

metabolic disorders, particularly diabetes. This journal is indexed on PubMed Central and MedLine. The manuscript management system is completely online and includes a very quick and fair peer-review system, which is all easy to use. Visit http://www.dovepress.com/ testimonials.php to read real quotes from published authors. 